International Journal of English Language Studies (IJELS)

ISSN: 2707-7578

DOI: $10.32996 /$ ijels

Website: https://al-kindipublisher.com/index.php/ijels

\title{
The Relevance of Linguistics Principles and Methods in English as a Second Language Classroom
}

\author{
Dr Ibrahim Juliet 8 (D) \\ Senior Lecturer, Department of English and Literary Studies, Kogi State University, Anyigba, Nigeria \\ $\triangle$ Corresponding Author: Dr Ibrahim Juliet, E-mail: ibrahimjuliet2014@yahoo.com
}

ARTICLE INFORMATION

Received: May 08, 2021

Accepted: June 14, 2021

Volume: 3

Issue: 7

DOI: 10.32996/ijels.2021.3.7.3

\section{KEYWORDS}

Second Language Classroom, linguistics principles and methods

\section{ABSTRACT}

This paper attempts to argue that linguistics principles and methods are relevant to effective classroom performance by teachers and effective learning by learners. It further argued that the old teaching methods are not entirely useless as they possess some communication characteristics that the linguistic principles still have to fall on. The paper, therefore, advocates for a strike in a balance between the traditional approaches and the current methods.

\section{Introduction}

English, an erstwhile foreign language in Nigeria, is now a second language and is fast becoming the first language of some children in the country. The language is formally learnt in the classroom environment and informally in social environments and homes. It has both official and political functions. In fact, it is the language of commerce at local, national and international levels and above all, it is the official language in Nigeria.

Considering the numerous and vital roles English plays and the secured anchor given to it wherever it is spoken (Ubhakwe 279), it can be said that English has come to stay in a country like Nigeria where it occupies a very important position and enjoys prominence or what Ayotunde Ogunsiyi technically terms 'dominance configuration' (24). It may continue to enjoy this position as long as it remains the unifying factor socially, culturally, politically and economically in Nigeria.

English is a compulsory subject that must be passed at any level of education. This is why parents (literates and illiterates) take pride in sending their children and wards to schools to learn the English language 'not only as a means to an end but as an end in itself' (Adebanjo 3). For instance, proficiency in the use of English guarantees a breakthrough into global communication links and the economy. Also, Nigeria's political, social, and economic development can only be gauged by the extent of the development of the language itself in Nigeria, as observed by Afolayan cited in Shola Babatunde (73).

The mass failure of students in school certificate examinations and failure to attain a credit pass in the subject is a serious issue. It is even more worrisome to see that the 'majority of candidates for each year's examinations are those who have been repeating the examination over a period of time' (3). In addition, some students in tertiary institutions like colleges of education, polytechnics and universities are not allowed to graduate until they record a pass in the 'Use of English' course offered in their first year.

Success in English language as a subject in secondary schools has also become a deciding factor in the pursuit of higher education. Yet student's performance keeps dwindling as more failure than success is recorded in school certificate examinations yearly. This is in spite of the early exposure of pupils to the language and the continuous study of the subject by learners.

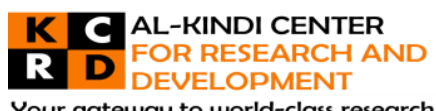

Your gateway to world-class research

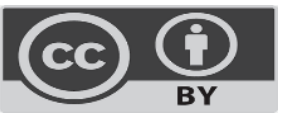

Published by Al-Kindi Center for Research and Development. Copyright (c) the author(s). This open access article is distributed under a Creative Commons Attribution (CC-BY) 4.0 license 
Moreover, a large percentage of English language teachers today are graduates of English language. The reason for this might be that either the learners are not serious about acquiring the necessary language skills or there are some deficiencies in the language classroom, as observed by Judith Mgbemena. On the other hand, both could be attributed to the cause of the downward trend in students' performance in the subject.

This paper, therefore, advances some linguistic principles and methods that can be used in the classroom by English language teachers to enhance their performance, make teaching activities relevant to the learners' needs and make language teaching a more result-oriented activity.

\section{Applied Linguistics in ESL Teaching}

A subset of Linguistics is 'Applied Linguistics' which Mgbemena (2005) says applies linguistic principles and theories to certain practical matters. These practical matters, she goes further, includes second language teaching. Language teaching, Broughton et al. observe, presupposes a theory of language and this is supplied by Applied Linguistics (39). In Applied Linguistics, what is applied is the theory of language and a description of one. Applied linguistics has expanded the frontier of language study to incorporate all instances and situations of the use of language in communication.

\section{The ESL Teacher in the Classroom}

A language teacher aims to speak English that is both intelligible and acceptable to the listeners since he is supposed to be a good model. But the teacher who possibly has been taught by a model that is non-native speaker (Ubahakwe 288) is confronted with enormous challenges such as the problem of negative transfer of mother tongue among others to the target language which is observable at all the linguistic levels but with particular manifestation at the phonological level. Therefore, the major problem confronting the ESL teacher is teaching the English sound system and oral communication skills.

A common teaching practice among teachers has been the use of imitation or mimicry which merely drills students in pronouncing the sounds. Learner's production under this method Gerry Abbott and Peter Wingard (1981) note is based on auditory clues or visual clues. This means the learner must be able to see the teacher's face to watch the lip movement like rounding or closing. This may only be possible in a class where there is no overpopulation. More so, this method of teaching does not help learners to distinguish between sounds adequately. It is even possible for learners to perceive wrongly what was said and thereby imitate wrongly as well. Some sounds are almost identical in articulation such as /s/ and /ts/, /f/ and /v/. For this, learners may need further explanation to know the differences and similarities between the two sounds.

Such practice as the one above has turned the learner's motivation for learning English to instrumental rather than integrative. Learners believe that their need is oral proficiency and not to develop a native speaker accent or think like a native speaker. Learners do not wish to accept an oral proficiency norm that they believe is socially non-functional in their immediate community. Therefore, an articulatory description would be appropriate to help the learner feel where and how a sound is produced. Though a full description of sounds may not be necessary, learner's attention can be drawn to some particular features of those sounds, such as lip shape, tongue position, voicing and a short directive.

An ESL teacher who is unaware of these steps may find himself in a fix, but an efficient one can still strategize his teaching methods to overcome some deficiencies inherent in teaching a second language outside its native environment. The teacher, for instance, can be guided by the curriculum and he can update himself with some linguistics texts, modem technological gadgets such as audio and video cassettes, diskettes and tape recorder that teach English sounds to aid his own perfection before going to teach the students. With these aids, the teacher can gain an in-depth knowledge of the English sound system and respond to any question thrown at him by students.

In secondary schools, paper three of their external examination is called 'Oral English', which is equivalent to Phonetics. Some of the teachers involved in teaching this aspect are purely 'localized' as they have no direct contact with the native speakers of the language. All they do, therefore, is to pronounce the way they feel is correct and make students imitate. This is because the teachers themselves have not internalized those sounds; they cannot give to students what they do not possess. They are just trying to satisfy the learners in the class but when they get outside the class where the language is put into full use with other persons, their inconsistencies start to show. The way they pronounce a word in the class will be different from how they will unconsciously pronounce the same outside the classroom environment. They merely drill students to recite sounds they themselves have not internalized. This is why they cannot actually describe those sounds they make students to imitate. For example, let us use a Yoruba speaker who teaches students oral English in the class how to pronounce the following words: 'cup', 'them', 'firm' and 'birth'. In the class, students are made to pronounce:

Cup - [Køp], Them - [ðam], Firm - [fa:m], Birth - [ba: $\square]$ 
But outside the class, the teacher himself pronounces:

Cup - $[\mathrm{k} \square \mathrm{p}]$, Them - [dem], Firm - [fam], Birth - [bat]

Once this inconsistency resulting from the mother tongue influence on the target language is noticed, students are likely to adhere to the one the teacher uses outside the class as that appears to be more relevant functionally in the immediate environment. This deficiency noticed in the teacher will not allow learners to aspire to attain proficiency in the appropriate articulation of English words. They see the class lesson as been more of artificiality.

The ESL teacher may not have an in-depth knowledge of phonology yet this should not prevent his efficiency in the language class (Wilkins 229). For instance, Broughton et al. attest to the fact that: 'There are people who teach the English language successfully without professional training or rigorous language study and are succeeding by virtue of those sensitive and sympathetic qualities which mark the natural teacher." (37)

All the teacher needs to succeed is to reflect in his teaching, the beliefs he holds about the needs of the learners, their ways of learning and the best method of motivating them (38). This, David Wilkins believes, will enable the teacher to decide what English to teach in a meaningful way and prepare well-organised lessons.

Also important is the ESL teacher's need to acquaint himself with current linguistics findings, especially those that aid language teachings, such as the findings from Contrastive Analysis (CA) of English language grammar and the learners' mother tongue in Error Analysis (EA). This will aid the teacher in studying grammatical errors of learners and also helps in identifying areas that need further attention in his teaching (Mgbemena 4). Knowledge of the teacher in Discourse Analysis (DA) will help the teacher teach appropriate use of language and interpret texts. The insight provided by linguistics, as observed by Wilkins, are ultimately very significant, however insubstantial. Linguistics increases the level of language teacher's awareness and thereby makes them more competent and better teachers.

\section{Language Teaching Methods}

There are many methods of teaching language, but they are not just there for any teacher to use. Before a teacher picks on a method, he should be familiar with its principles or details to be successful in its use. This is because whatever method an ESL teacher adopts for his lessons will directly impact the ability of students to acquire and use the language adequately. For example, if a teacher decides to make his ESL class active and participatory, learners will be motivated to learn as there will be occasions for learners to ask questions on areas of difficulties and possibly receive responses from the teacher. But if the teacher, for instance, decides, on the other hand, to make it dull or artificial, learners may lose interest in whatever is going on around them.

The chosen principle must be explicitly stated to the students so that the same knowledge acquired from the principle can be transferred to solve language problems outside the classroom, Mgbemena advises. There are several language teaching methods, but only a few are reviewed in this paper as a background base since the paper aims to propose some linguistic principles and methods for teaching English as a second language. These few include; Teacher Talk,' 'Grammar Translation Method', 'Direct Method', and Audio-Lingual Method.

The first method to be examined is the language of instructions coded Teacher Talk. Teacher Talk' is seen as a register, the frequencies of coded behaviour in the classroom language. In this method, it is the teacher who does two-third of the talking while the students listen. Students are not allowed to use the language to express themselves in the target language as expected. This is because the aim is to make learners acquire the linguistic structure of speech as well as control of language. This method is made to work cannot help students learn as they are not allowed to participate in the classwork. There is no room to ask questions that can elicit responses from the teacher and thereby make the exercise participatory enough. Some teachers are unaware of Teacher Talk' and 'Classroom Discourse.' The teacher is not expected to dominate classroom discourse. Students should be made to participate in the classwork by asking questions and by responding to teacher's questions. This will reduce the level of anxiety in the classroom atmosphere.

\subsection{Grammar Translation Method}

It is acclaimed to be the first method for teaching language. This method trains the mind through logical analysis and memorization. It enables learners to acquire large vocabulary and grammar rules but no room to acquire many skills or fluency. Emphasis was on grammar structure and memorization of rules and a list of vocabulary. Communication skills and teaching of pronunciation were neglected. Also, there was no link between the environment and the experience of learners. It is equally prescriptive. All these are not said to portray the method as a completely useless one, but it is unlikely to succeed if it is adopted as the only or main method. (Abbott and Wingard 281). 


\subsection{Direct Method}

It is sprang up as a result of the reaction against the 'Grammar Translation Method' inadequacies. Though this method emphasizes oral skill, the grammar of the target language was not explicitly taught. It emphasizes the importance of listening and speaking since the principle arose as a result of the need for effective language learning. It encourages the full participation of learners in the learning process and encourages the use of teaching aids. But no systematic practices of structures may occur in the course of free conversation. (Alhassan 79).

\subsection{Audio-Lingual Method}

This method emphasizes habit formation, drilling and repetition but avoids mimicry and memorization (Tswanya 6). Chomsky's Transformational Generative Grammar challenged this view that language is not a process of habit formation but it rather has to do with the innate ability of the learner and is not based on observable behaviour. This method was challenged seriously as it is not capable of making learners speak a language. This dissatisfaction about the 'audio-lingual method' was part of what set the stage for a communicative competence approach that is learner-centred to language teaching and learning.

The traditional view of language, such as the grammar-translation method, has produced a teaching method which selected the major grammar rules with their exceptions and taught them in a certain sequence. This, Broughton et al. noticed, has for years produced generations of non-communicators (39). Also, the structural approach that allows many learners to use language-like behaviour such as the audio-lingual method, also reflects essentially non-communicative views of the nature of language. Broughton et al. believe 'are as practical as driving lessons in an immobilized car' (39). Language, it is noted, is a social behaviour that functions within the context of the situation, which makes it difficult to divorce linguistic forms from their setting. This led to the emergence of 'Situational' approach to language teaching in which a series of appropriate settings are considered. Although new methods or approaches signify a certain break from the old, there is still a link with the past as positive aspects of previous paradigms are incorporated into the new method.

\section{Linguistics Principles in Language Teaching}

The tools Applied Linguistics employs to study language include 'Discourse Analysis' (DA) 'Contrastive Analysis' (CA) and 'Error Analysis' (EA). All these tools are referred to as Applied Linguistics principles and they can be used to teach English language.

Since the demise of audio-lingual method of language teaching (Tswanya 6) language, pedagogy has gone beyond the emphasis on teaching linguistic competence to the teaching of communicative competence with its emphasis on meaning and its learner- centered approach. This approach, it is noted, still incorporates some aspects of communicative teaching that are characteristic of other methods that preceded it. This makes it possible to contribute more effectively to language teaching than either the 'Grammar Translation Method' or 'Audio-Lingual Method'.

Within communicative competence, topics such as the rule of words, sentence formation, spelling, punctuation and linguistic semantics are considered. There is also socio-linguistic competence that includes rules of appropriateness, grammatical forms, discourse competence and strategic competence (Ibrahim and Atomode, 8). Strategies of acquiring skills, using language to suit the categories of audience, producing a text where various components relate logically and cohesively, and keeping conversation going, by all means, are all considered in communicative competence. Each of the principles applied to teach the above various aspects is considered one after the other. These are; 'Discourse Analysis', 'Contrastive Analysis', and 'error Analysis.'.

\subsection{Discourse Analysis (DA)}

The study of the functional use of language, provides necessary insight into the use of linguistic tools for the explication of text. It studies language in the real context and is not concerned with isolated decontextualized sentences. As a result, it can be used to teach grammar rules, word order and vocabulary. To attain command of English language, learners have to be exposed to it in genuine circumstances with natural frequency or study both the lexis and syntax thoroughly if learners have come in contact with natural input. According to Ibrahim and Atomode, classroom discourse seems to be the best way of systematizing the linguistic code that learners are to acquire.

In the past, an effort was towards teaching linguistic competence, but the current efforts in teaching and syllabus design are now devoted to teaching communicative competence within which 'grammatical competence', 'sociolinguistic competence' and 'discourse competence' are considered.

In teaching grammar, adequate attention should be given to the traditional concepts such as clause, pronoun, adverbial, conjunction, phrase, and so on. To establish the link between grammar and discourse, the above concepts must also be related to the other discourse terms such as 'theme', 'rheme', 'substitution', 'ellipsis', and 'reference', anaphoric, cataphoric and exophoric( Ibrahim and Atomode 8). The most outstanding role in producing advanced discourse and requires much attention on the part of teachers and learners, Ibrahim and Atomode note, is that of words and phrases that indicate the internal relation 
of sections of discourse, namely conjunctions. Among the several conjunctions identified by M. McCarthy, the most recurrent are; 'where', 'and', 'but', 'so', 'then'. These contribute to the cohesion of the text and are also used when a conversation participant takes his turn to speak to link his utterance to what has been said before.

DA also studies language in context. This is relevant in the area of teaching of reading and comprehension, where meaning to some lexical items in passages or texts are sourced from those words that co-occur with them or from those words that surround them that is, the context within which they occur without necessarily referring to dictionaries. Studying language in its context of situation will allow accurate interpretation of utterances and texts.

In the area of stylistics, DA can be used to teach occasions of writer's 'creativity' and 'style' for example. There are instances where writers deviate deliberately in their use of language for stylistic impact. An occasion like this can be differentiated from grammatical errors or mistakes through explanation. For instance, the acknowledged English word order is SV (0)(A). A writer may decide to turn this round to create style such as;

$\frac{\text { A man of valour came here }}{\mathrm{S} V \mathrm{~A}}$
Becoming; cameherea man of valor
$\mathrm{V}$ Herecamea man of valor

In DA the justification of this usage and the aesthetic appeal should be pointed out to learners. For practice, they can also be asked to try and construct similar structures. Most students have problems with developing their ideas in logical sequences. Through text- analysis, students can be taught how to develop ideas into phrases, clauses, sentences, paragraphs and even text. The teacher can organize group activities such as debates and stories that can promote or entail communication skills. These practical tasks, Mgbemena opines, can make the English language classroom participatory (7). With the knowledge of DA, students communication skills can be developed. For example, students can be given some topics on dialogue or narrative to write on and present before the class.

Through this writing, they can become familiar with rules that govern conversation or discourse, such as how to open conversation, develop conversation using the convention of turn-taking to accomplish various functions of language, shift the topic, and interrupt and how to close conversation. The ability to effectively manage or apply these rules can help students in developing their composition sequentially from phrase to clause, a clause to sentence, sentence to paragraph and paragraph to text. This can also help in producing a coherent passage of text. An ESL teacher can watch to see whether these rules of discourse are correctly applied. Where they are not, the teacher can come in to subtly correct and reinforce.

The introduction of discourse into language teaching does not mean jettisoning vocabulary teaching in a discourse oriented syllabus, so vocabulary lessons will still be considered. The inclusion of discourse in the syllabus is just to bring discourse aspect into vocabulary teaching alongside traditional and recent, more communicative approaches. For instance, a discourse-oriented approach to vocabulary teaching will pay attention to context and co-text within which the words appear. This will help in the teaching and learning of register and formality. (8) The knowledge of vocabulary-oriented discourse devices support language learning in diverse manners. Most importantly, it ought to bring students to organize new items of vocabulary into groups with a common context of use to make them realize how the meaning of a certain word might change with circumstances of its use or co-text. This will help to enhance the learner's ability to choose the appropriate synonyms, collocation or hyponyms as noted by McCarthy. Through the use of discourse, students can be exposed to various fields such as Engineering, Medicine, Law, and so on, where they can encounter various registers that can help increase their vocabulary.

\section{2. Contrastive Analysis (CA) in ESL Teaching}

Contrastive analysis is a systematic comparison and contrasting of the native and the target (TL) systems. The major barrier to the acquisition of second language (L2) according to the behaviourist and the structuralists is the native language (L1). A scientific structural analysis of the two languages, it is believed, will provide taxonomy of linguistic contrast between them. This will enable linguists to predict the difficulties a learner would encounter. An -accurate description of the two languages and matching those two descriptions against each other will enable the teacher to determine the valid contrast between them.

For instance, in Yoruba language, the nasalized / i / vowel as in 'pin' meaning 'share' and the nasalized J/ כowel as in 'pon' meaning 'ripe' can be contrasted with the pure English vowels /i/ and $/ \mathrm{J} /$ which when used mean different thing can be contrasted. These vowels will cause problems to the English speaker when a text containing these vowels is given for them to read. In a situation like this, the teacher will have to describe the two languages explicitly using the tool of formal grammar. 
In contrasting the two languages, the teacher does not need to contrast every fact of the two languages. All he needs to do is to select certain forms of linguistic items, rules, structure and contrast. Following this, the teacher maps one linguistic system into the other and a specification of the relation of one system to the other is done. This will enable the teacher to predict areas of difficulty, describe the pattern that will cause difficulties in learning and those that will not.

The outcome of this contrast will enable the teacher identify areas of his teaching that needs further attention or where he needs to adopt a new strategy in his teaching.

\section{3. Error Analysis (EA) and ESL Teaching}

One of the early approaches to validating the mentalist approach to language learning is the analysis of learner's error in second language learning. Error Analysis (EA) studies learners' language intending to identify the learners' mistakes, figure out the causes, and identify the significance of such errors. The error that M. Olaseinde notices is a breakdown in the teaching and learning situation, but Noam Chomsky quoted in Olaseinde says it is necessary to prove that learning is taking place. (112).

EA is an important linguistic tool in studying ESL. This is because it provides insight into how languages are leant and permits rules for learners' interlingual systems. Through EA, what is left to be covered by the teacher or what remains to be learned by learners are discovered. Through EA, the teacher can get feedback on how effective his teaching materials have been and how appropriate his teaching techniques are. EA provides guidelines that govern the teaching behaviour of teachers and provides avenue for evaluating practices. Where possible it adjusts or adapts practices. Through this, principles and practices can become compatible.

Through the analysis of students' errors, the teacher can help learners in their areas of deficiencies. This is because problem areas will be identified and the teacher can plan for remedial work. Equally, based on his studies of error, the teacher can plan programmes for future groups, thereby making teaching easy for himself (Abbott and Wingard 214).

While studying errors in student's work, sources of those errors should be made to ascertain whether the source of such errors can be identified as either 'interlingual' or 'intralinguaT. Interlingual is caused by Mother Tongue (MT) transfer, while intralingual errors come up as a result of faulty overgeneralization about the rules of the Target Language (TL). For example

'He buyed a car1, 'Where is you', 'Does he comes'

This study can further help the teacher ascertain whether the errors result from 'carelessness' or 'hyper-correction' resulting from 'over emphasis' on items. Contrastive analysis (CA) may cause problems to effective learning. Most teachers tend to make learners believe that items pointed out by CA or EA as areas of difficulties are very important. As a result, learners make frantic efforts to learn, thereby overusing them. As the teaching of concord (subject verb agreement), it is clear that 'he' is only the 3rd person singular pronoun that can combine with present simple verbs that end with (s) such as he comes, it comes, she comes.

This rule can be over generalized to cover the first person singular and plural pronouns such as 'I', 'we', 'they', to have 'I comes', 'they comes', 'we comes'.

The study of this type of error will reveal the source(s) of errors and helps the teacher assess his method/technique of teaching and adjust likewise. This can make both learning and teaching easy even for future programmes as teachers can see where they are at fault and adjust accordingly. This is to say EA serves as a mirror to the teacher for self-assessment and as a guide or a monitor. If the error made is discovered to be generally made, then the teacher needs a personal assessment for adjustment. The relevance of EA is for both the teacher and learners.

\section{Conclusion}

This paper sets out to assess the importance of linguistic principles and methods in English as a second language classroom. English language teachers in the past tend to view 'grammar' as an exclusively sentence-level phenomenon. This has affected negatively the way 'grammar' is described and taught. This makes English language teaching in secondary schools in Nigeria to be deficient as it does not provide the desired objectives for teaching and learning a second language.

This study discovered that a discourse-oriented approach to teaching and learning in English as a second language is what learners need to succeed in comprehending and producing meaningful utterances in English. But a discourse oriented syllabus still has to consider vocabulary lessons as this will enable teaching to focus attention on context and co-text within which words appear.

Although this new approach to language teaching and learning signifies a certain break from those of old methods, there is still a need to incorporate the previous paradigms into the new methods of teaching as old methods are found not to be completely useless; they possess some communication characteristics that the linguistic still have to fall on. 
During this study, the researcher encountered some problems with learners where teachers made learners focus seriously on some areas of perceived problems (errors) Here. Learners started over emphasizing some rules that later led to overgeneralization of rules (misapplying rules). Moreover, most of the predicted errors were not found in learners' utterances.

This study's significance lies in the fact that those identified problem areas by contrastive analysts and error analysts will enable teachers to make self-assessment in their teaching methods and adjust their teaching methods where necessary. This is because those identified errors will serve as guides or monitor to teachers.

Therefore, it is suggested that both linguistic and communicative competence need to blend together to get the best out of the chosen teaching methodology. It is equally suggested that a balance between traditional approaches and current linguistic methods so the classroom can wear a functional outlook to enable students to utilize the knowledge acquired from the classroom to confront educational challenges.

\section{References}

[1] Abbott, G., Greenwood, J., Douglas, M., \& Peter, W. (1989). The teaching of english as an intemational language: a practical guide.

[2] Adebajo, M. (2008). Factors Affecting Students Poor Performance in English Language in West African School Certificate Examination in llesha Local Government Area." A Paper Presented at the $6^{\text {th }}$ Annual Conference of English Language Teaching Today in Federal University of Technology, Akure.

[3] Alhassan, H. (2009). Introduction to Concepts and Methods in Applied Linguistics. Kaduna: Euneeks and Associates,.

[4] Ayotunde, O. (2008). . Introduction to English as a Second Language. National Open University of Nigeria, Abuja,.

[5] Babatunde, S.T. (2007). Sociolinguistic Analysis of Selected Nigerian English (NE) Metaphors." In Sociolinguistics in the Nigerian Context, (ed.) Adeyanju, Dele. Ife: Obafemi Awolowo University Press Ltd, 2007,145-176.

[6] Broughton et al. (1978). Teaching English as a Foreign Language, $2^{\text {nd }}$ ed. London: Routledge and Kegan Paul.

[7] Crystal, David. Linguistics. New York: Penguin. 1977. Print.

[8] Ibrahim, J. \&. Atomode, D. (2012). Discourse Analysis and the Teaching of English Language in Nigerian Secondary Schools. Ibadan: Moyosore

[9] Igboanusi, H. (2002). Perspective for English Language Teaching in Nigeria in the Context of Global English." In Language, Meaning and Society Papers in Honour of E.E. Adegbija.( eds.) Babatunde, S.T. and Adeyonju, Dele. llorin: Haytee Press and Publishing Co..

[10] McCarthy, M. (1994). Discourse Analysis for Language Teachers. Cambridge: Cambridge University Press.

[11] Mgbemena, J. (2005). Towards the Application of Linguistic Principles and Methods in ESL Classroom" A Paper Presented at third edition of English Language Teaching Today in University of Agriculture, Abeokuta.

[12] Olaofe, E. (2012). Linguistics and Language Teaching. Ibadan: Mcroffs.

[13] Olaseinde, M.O. (2002). Error Analysis and Remedial Pedagogy." In Language, Meaning and Society, (eds.) Babatunde, S.T. and Adeyonju, Dele. Ilorin: Haytee Press and Publishing, 2002. 111-128.

[14] Tswanya, K. (2008). English Language Teaching: Abundant Methodologies, Limited Classroom Applications." A Lead Paper Presented at the $6^{\text {th }}$ English Language Teaching Today Annual Conference, University of Technology, Akure. 